\title{
TES KOGNITIF DIAGNOSTIK UNTUK MENDETEKSI KESULITAN BELAJAR SISWA SEKOLAH DASAR
}

\author{
Sri Budyartati *
}

\begin{abstract}
Misconception refers to a concept which is neither in accordance with a scientific nor accepted by experts of a scientific body. Concepts are brought by students through observations or their first hand experiences of daily life. Students' continuous misconceptions may hinder their building of scientific conceptions. Learning which does not take into account misconceptions leads learning difficulties and ends in students' low achievement. In constructivistic learning, what does matter is that the learners themselves build their knowledge, rather than that the teacher transfers the knowledge. An implication of the constructivistic view for schools is that knowledge cannot be simply transformed from the teacher's mind to the students'. It is actively constructed by the students themselves through first hand experiences. Teachers' role, therefore, changes from the source and the giver of knowledge into the facilitator, and, by so doing, the essence of education lies on the learners rather than on the teacher. Cognitive Diagnostic Assessment (CDA) for education is designed specifically to assess the knowledge structure and the process of students' ability to supply information with regard to their cognitive strength and weakness.
\end{abstract}

Key words: Cognitive Diagnostic Assessment, Detecting Difficulties

\begin{abstract}
Abstrak
Miskonsepsi merujuk pada suatu konsep yang tidak sesuai dengan pengertian ilmiah atau pengertian yang diterima para pakar dalam suatu bidang. Konsep yang dibawa siswa diperoleh dari pengamatan atau pengalaman mereka di masyarakat atau dalam kehidupan sehari-hari. Miskonsepsi pada siswa yang muncul secara terus menerus dapat mengganggu pembentukan konsepsi ilmiah. Pembelajaran yang tidak memperhatikan miskonsepsi menyebabkan kesulitan belajar dan akhirnya akan bermuara pada rendahnya prestasi atau hasil belajar siswa. Dalam pembelajaran yang berorientasi konstruktivistik, guru tidak hanya sekedar memberikan pengetahuan pada siswa, siswa harus membangun sendiri pengetahuan di dalam benak siswa. Implikasi dari pandangan
\end{abstract}

* Sri Budyartati adalah Dosen PGSD IKIP PGRI Madiun dan Kandidat Doktor Universitas Negeri Yogyakarta 
konstruktivisme di sekolah ialah pengetahuan itu tidak dapat dipindahkan secara utuh dari pikiran guru ke siswa, namun secara aktif dibangun oleh siswa sendiri melalui pengalaman nyata. Peran guru otomatis berubah, dari sumber dan pemberi informasi menjadi pendiagnosis dan fasilitator, sehingga eksistensi dalam mendidik tidak terfokus pada pendidik melainkan pada pembelajar. Cognitive diagnostic assessment (CDA) atau penilaian diagnosis kognitif untuk pendidikan disusun untuk mengukur struktur pengetahuan secara khusus dan proses kemampuan siswa untuk menyediakan informasi tentang kelemahan dan kekuatan kognitif mereka.

Kata Kunci: Tes Kognitif Diagnostik, Deteksi Kesulitan

\section{A. Pendahuluan}

Pendidikan merupakan upaya manusia untuk memperluas cakrawala pengetahuan. Pendidikan memiliki peranan yang amat penting dan salah satu faktor yang mendapatkan perhatian dari pemerintah. Hal ini dapat dilihat melalui penyediaan fasilitas yang cukup memadai serta peningkatan kualitas pendidikan. Pemerintah selalu berperan untuk meningkatkan kualitas pendidikan melalui pendidikan formal yang terbukti bahwa dari tahun ke tahun kurikulum pendidikan mengalami penyempurnaan dan pengembangan secara terencana, terarah, dan berkesinambungan. Penyempurnaan dan pengembangan kurikulum ini tidak terlepas dari peran serta oleh seorang guru sebagai penerjemah dan pelaksana isi kurikulum tersebut. Penyempurnaan dan pengembangan kurikulum tersebut terbukti dengan telah adanya Kurikulum 1994 yang selanjutnya disempurnakan pada Kurikulum 1999. Pada perkembangan selanjutnya kurikulum dirasa perlu adanya perubahan dan penyesuaian dengan perkembangan, sehingga tersusunlah Kurikulum Berbasis Kompetensi (KBK) Tahun 2004.

Selanjutnya pada tahun 2006 kurikulum kembali mengalami perubahan, yang semula KBK diganti dengan Kurikulum Tingkat Satuan Pendidikan (KTSP) yang merupakan penyempurnaan dari kurikulum sebelumnya dengan tujuan akan terjadinya perubahan kualitas dari pendidikan. Masih ditemukannya yang mengajar dengan menggunakan model pembelajaran yang bersifat konvensional, yaitu model pembelajaran yang semua kegiatan pembelajarannya terpusat pada guru. Hal seperti inilah yang membuat siswa hanya terpaku untuk menerima materi atau bisa disebut siswa hanya sebagai obyek dalam setiap proses pembelajaran, sehingga perkembangan pengetahuan siswa hanya sebatas apa yang disampaikan oleh guru tanpa memperhatikan potensi-potensi siswa yang harus dikembangkan. Dalam pembelajaran konvensional yang dilakukan oleh guru tersebut, sering terjadi suatu salah pemahaman oleh siswa. Kesalahpahaman atau yang disebut dengan miskonsepsi ini terjadi karena pengetahuan awal siswa atau pengalaman siswa berbeda dengan yang dijelaskan oleh guru.

Banyak hal yang dapat diperoleh melalui pengalaman dan hal tersebut menjadi sebuah pengetahuan awal ketika anak tersebut memasuki pendidikan formal. Pengetahuan awal yang dimiliki siswa belum tentu benar atau salah, karena pengetahuan ini diperoleh siswa dari pengalaman yang berbeda-beda dan 
sumber informasi yang tidak akurat. Padahal penguasaan pengetahuan awal yang dimiliki seseorang sangat berpengaruh terhadap perolehan pengetahuan di sekolah. Suparmo (2005: 3) menyatakan tidak jarang bahwa konsep siswa, meskipun tidak cocok dengan konsep ilmiah, dapat bertahan lama dan sulit diperbaiki atau diubah selama pendidikan formal. Miskonsepsi yang paling banyak terjadi pada siswa disebabkan konsep awal (prakonsepsi) yang kemudian dibawa ke pendidikan formal. Hal ini sering terjadi pada siswa sekolah dasar (SD). Sejak kecil, seseorang sudah mengkontruksi konsep-konsep melalui pengalaman sehari-hari sehingga seseorang dikatakan sudah mengalami proses belajar sejak awal.

Miskonsepsi merujuk pada suatu konsep yang tidak sesuai dengan pengertian ilmiah atau pengertian yang diterima para pakar dalam suatu bidang. Konsep yang dibawa siswa diperoleh dari pengamatan atau pengalaman mereka di masyarakat atau dalam kehidupan sehari-hari. Miskonsepsi pada siswa yang muncul secara terus menerus dapat mengganggu pembentukan konsepsi ilmiah. Pembelajaran yang tidak memperhatikan miskonsepsi menyebabkan kesulitan belajar dan akhirnya akan bermuara pada rendahnya prestasi atau hasil belajar siswa. Sebagai contoh miskonsepsi yang ditemui dalam materi tentang gaya pada siswa Kelas V, guru menampilkan gambar seorang anak yang mendorong sebuah mobil. Kemudian guru bertanya pada siswa apakah mobil itu mendapat gaya meski mobil tersebut tidak bergerak?

Ternyata ada siswa yang menjawab bahwa mobil tidak mendapat gaya. Hal tersebut di atas merupakan salah satu contoh miskonsepsi yang terjadi dalam pembelajaran Ilmu Pengetahuan Alam (IPA). Mobil yang mendapat dorongan atau gaya tetapi tidak bergerak akan tetap mendapat gaya, karena gaya adalah suatu usaha dorongan atau tarikan yang diberikan pada suatu benda. Jadi mobil yang diam itu tetap memperolah gaya, gaya yang terjadi pada mobil adalah gaya gravitasi tetapi tidak mendapat usaha. Gaya yang terdapat pada mobil didapat dari massa dikalikan dengan gravitasi atau dengan rumus $\mathrm{F}=\mathrm{m}$.g. Apabila miskonsepsi ini tidak diatasi dengan benar, maka akan mempengaruhi pemahaman siswa terhadap konsep IPA yang sebenarnya dan berdampak pada hasil belajar siswa yang rendah.

Bertolak pada permasalahan diatas, maka dalam pembelajaran khususnya pada mata pelajaran IPA, guru seharusnya tidak menggunakan model pembelajaran yang konvensional. Apabila guru mengajar hanya dengan menerangkan, maka miskonsepsi ini akan terjadi terus menerus dan berpengaruh terhadap pengetahuan yang akan mereka terapkan dalam kehidupan sehari-hari siswa. Sebagai fasilitator pembelajaran, guru hendaknya memiliki kemampuan untuk mengenali dan menggali pengetahuan awal siswa, terutama pengetahuan awal yang salah agar tidak terjadi miskonsepsi yang berkepanjangan. Selain itu, guru juga hendaknya memiliki kemampuan untuk mengatasi miskonsepsi yang terjadi pada siswa karena konsep yang siswa bawa, meskipun keliru, tetapi dapat menjelaskan beberapa persoalan yang mereka hadapi dalam kehidupan mereka.

Oleh karena itu, seorang guru IPA hendaknya memperhatikan pengetahuan awal siswa dan terpusat pada siswa. Guru sebagai fasilitator dalam pembelajaran IPA dapat menerapkan beberapa pendekatan, antara lain pendekatan lingkungan, 
pendekatan keterampilan proses, pendekatan inqury (penyelidikan), dan pendekatan terpadu (Samatowa, 2010). Pada proses pembelajaran di sekolah, sangat dianjurkan pada guru untuk menggunakan model dan metode pembelajaran yang lebih menantang dan mengajak siswa untuk mengkonstruksi pengetahuan baru melalui pengalaman belajar yang tepat. Pembelajaran yang dirasa tepat untuk mengatasi masalah miskonsepsi dan meningkatkan pemahaman siswa terhadap konsep IPA adalah pembelajaran yang berorientasi konstruktivistik. Dalam pembelajaran yang berorientasi konstruktivistik, guru tidak hanya sekedar memberikan pengetahuan pada siswa, siswa harus membangun sendiri pengetahuan di dalam benak siswa. Guru dapat memberikan kemudahan untuk proses ini, dengan memberikan kesempatan siswa untuk menemukan atau menerapkan ide-ide mereka sendiri, mengajar siswa menjadi sadar dan secara sadar menggunakan strategi mereka sendiri untuk belajar (Trianto, 2007:13).

Implikasi dari pandangan konstruktivisme di sekolah ialah pengetahuan itu tidak dapat dipindahkan secara utuh dari pikiran guru ke siswa, namun secara aktif dibangun oleh siswa sendiri melalui pengalaman nyata. Peran guru otomatis berubah, dari sumber dan pemberi informasi menjadi pendiagnosis dan fasilitator, sehingga eksistensi dalam mendidik tidak terfokus pada pendidik melainkan pada pembelajar. Dalam pembelajaran yang menggunakan pendekatan konstruktivistik ada beberapa hal yang diutamakan, seperti mengutamakan pembelajaran yang bersifat nyata, mengutamakan proses, menanamkan pembelajaran dalam konteks pengalaman sosial, pembelajaran dilakukan dalam upaya mengkonstruksi pengalaman. Dengan menggunakan pendekatan konstruktivistik ini, diharapkan miskonsepsi yang terjadi pada siswa dapat diminimalkan dan pemahaman tentang konsep IPA dapat ditingkatkan sehingga hasil belajar siswa juga dapat meningkat.

\section{B. Pembahasan}

\section{Tes Kognitif Diagnostik}

Cognitive diagnostic assessment (CDA) atau penilaian diagnosis kognitif untuk pendidikan disusun untuk mengukur struktur pengetahuan secara khusus dan proses kemampuan siswa untuk menyediakan informasi tentang kelemahan dan kekuatan kognitif mereka.Untuk mengetahui sikap siswa terhadap pengelolaan pengetahuan, maka terdapat lima langkah untuk mengetes pengembangan psikologi siswa. Nichols menguraikan lima langkah untuk mengetes pengembangan psikologi siswa (Gierl, 2007:11), yakni:

a. Substantive theory construction: this first step requires the development of a model or theory that characterizes the hypothesized knowledge structures and processes required to perform (respond to) the assessment. In addition, the item variables that invoke particular cognitive processes and knowledge structrures must be identified;

b. Design selection: this second step, guided by the model or theory developed in step 1, requires the test developer to choose the observation and measurement design.the test items chosen will be selected (or created) with the expectation that test takers will respond in predictable ways, with the processes and knowledge structures identified in step 1, to the items; 
c. Test administration: this third step involves important details of the environment and context in which test takers complete their assessments such as item format, medium of item presentation, and setting of the test. It is recommended that decisions about the test administration should be informed by research on how different test administration variables influence performance;

d. Response scoring: this fourth step involves assigning scores to test takers that are informative of the construct measured by the test. Nichols indicates that response scoring (as design selection) operationalizes the assessment design;

e. Design revision: this fifth step involves reexamining the assessment design to see whether it supports the model or theory on which it is based. The results of the assessment are used to revise the subtantive base of the assessment. Nichols states, "As with any scientific theory, the theory used in development is never proven; rather; evidence is gradually accumulated that supports or challenges the theory".

Menurut Nichols cara untuk mengetes kemampuan psikologi adalah:

a. Substantive theory construction

Teori konstruksi substansi: langkah pertama membutuhkan pengembangan model atau teori yang mencirikan struktur pengetahuan hipotesis dan proses yang diperlukan untuk melakukan (menanggapi) penilaian. Selain itu, sebuah variabel yang meminta proses kognitif tertentu dan struktur pengetahuan harus diidentifikasi.

b. Design selection

Seleksi desain: langkah kedua ini, dipandu oleh model atau teori yang dikembangkan pada langkah 1, mengharuskan pengembang tes untuk memilih sebuah observasi dan pengukuran uji disain. Sebuah tes yang terpilih akan diseleksi (atau diciptakan) dengan harapan bahwa pengambil test akan merespons arah yang dapat diprediksi, dengan proses dan struktur pengetahuan yang diidentifikasi pada langkah 1 , ke sesuatu hal.

\section{c. Test administration}

Tes Administrasi: langkah ketiga ini meliputi rincian penting dari lingkungan dan konteks dimana pengambil penilaian mereka uji yang lengkap seperti format, media presentasi, dan pengaturan dari sebuah tes. Disarankan bahwa keputusan tentang administrasi tes harus diberitahukan sesuai dengan penelitian tentang bagaimana perbedaan variabel uji administrasi mempengaruhi kinerja.

d. Response scoring

Respon skor: langkah keempat ini meliputi memberikan skor untuk pengambil tes yang gagasannya berisi keterangan yang diukur dengan ujian. Nichols menunjukkan bahwa respon skor (seperti pemilihan desain) mengoperasikan desain penilaian.

e. Design revision

Desain revisi: Langkah kelima ini meliputi memeriksa kembali desain penilaian untuk melihat apakah mendukung model atau dasar teorinya. Hasil penilaian digunakan untuk merevisi substansi dasar penilaian. Nichols 
menyatakan, seperti halnya teori ilmiah, teori yang digunakan dalam pembangunan tidak pernah terbukti, melainkan; bukti secara bertahap akumulasi atau tantangan yang mendukung teori ini.

Setiap individu mempunyai pemahaman terhadap apa yang mereka ketahui. Gierl (2007:72) menjelaskan: the central idea is that human understanding and rationality are consequences of the human capacity for communicative action. Atau dengan kata lain gagasan utamanya adalah bahwa pemahaman manusia dan rasionalitas merupakan konsekuensi dari kemampuan manusia untuk melakukan tindakan komunikatif. Tindakan komunikatif merupakan tindakan yang dilakukan seseorang dengan orang lain agar mereka dapat saling mengerti, bekerja sama yang dibutuhkan dalam kehidupannya.

Pengetahuan kognitif harus memberikan derajat pemahaman. Lebih lanjut Gierl (2007:81) menjelaskan: details about the depth of the person's understanding, including contextual detail, are required to make sense of what is going on. As with our previous ponit, cognitive models alone cannot be used to specify degrees of understanding. Rincian tentang dalamnya pemahaman seseorang, termasuk detail kontekstual, diharuskan untuk memahami apa yang sedang terjadi. Model kognitif saja tidak dapat digunakan untuk menentukan derajat pemahaman. Oleh karena itu, untuk mengatasi miskonsepsi pada siswa, diperlukan suatu tindakan pemahaman konsep pada siswa tanpa mengesampingkan kognitif siswa.

\section{Miskonsepsi sebagai Salah Satu Bentuk Kesulitan Belajar}

Miskonsepsi adalah suatu konsep yang tidak sesuai dengan konsep yang diakui oleh para ahli. Novak mendifinisikan miskonsepsi sebagai suatu intepretasi konsep-konsep dalam suatu pernyataan yang tidak dapat diterima. Miskonsepsi atau salah konsep menunjuk pada suatu konsep yang tidak sesuai dengan pengertian ilmiah atau pengertian yang diterima para pakar dalam suatu bidang tertentu (Suparmo, 2005:4). Bentuk miskonsepsi dapat berupa konsep awal, kesalahan, hubungan yang tidak benar antara konsep-konsep, gagasan intuitif atau pandangan yang naif. Fowler menjelaskan miskonsepsi sebagai pengertian yang tidak akurat akan konsep, penggunaan konsep yang salah, klasifikasi contohcontoh yang salah, kekacauan konsep-konsep yang berbeda, dan hubungan hirarkis konsep-konsep yang tidak benar (Suparmo, 2005:5). Bodner menjelaskan, penyebab dari resistennya sebuah miskonsepsi miskonsepsi karena setiap orang membangun pengetahuan persis dengan pengalamannya (Sihite, 2008:7).

Sekali kita telah membangun pengetahuan, maka tidak mudah untuk memberi tahu bahwa hal tersebut salah dengan jalan hanya memberi tahu untuk mengubah miskonsepsi itu. Jadi cara untuk mengubah miskonsepsi adalah dengan jalan mengkonstruksi konsep baru yang lebih cocok untuk menjelaskan pengalaman kita. Kita dapat mengetahui bahwa sebelum mengikuti pembelajaran di kelas, siswa memiliki konsep awal. Sebelum mengikuti pembelajaran secara formal di sekolah, siswa ternyata sudah membawa konsep tertentu yang mereka kembangkan lewat pengalaman hidup mereka sebelumnya. Konsep yang dibawa siswa dapat sesuai dengan konsep ilmiah tetapi juga dapat tidak sesuai dengan 
konsep ilmiah. Sebagai contoh, bahwa banyak siswa kelas V bahwa mobil yang didorong meskipun tidak bergerak berarti mobil tersebut tidak mendapat gaya karena mobil tidak bergerak.

Selain itu miskonsepsi tentang gaya yang terdapat pada siswa SD adalah siswa beranggapan benda yang jatuh ke bawah karena adanya gravitasi, tetapi benda yang ada di bawah atau diam di bawah tidak mendapat gaya gravitasi. Benda yang jatuh ke bawah dipengaruhi oleh gaya gravitasi atau gaya tarik bumi, sedangkan benda yang pada awalnya ada di bawah tetap mendapat gaya gravitasi meski tidak ada gerakan atau perpindahan tempat. Proses pembelajaran di SD yang dilakukan oleh guru-guru masih didominasi dengan kegiatan ceramah dan pemberian tugas. Guru berusaha menjelaskan konsep-konsep yang dipelajari, kemudian siswa hanya mendengarkan dan mencatat. Pembelajaran yang seperti ini akan membuat siswa untuk mengetahui dan menghafal konsep-konsep tersebut yang berbeda dengan pengalaman awal siswa. Hal seperti itulah yang akan membuat miskonsepsi siswa berjalan terus dan siswa sulit memahami konsep yang sebenarnya.

Pengetahuan menurut pendekatan konstruktivistik bukanlah kumpulan fakta dari suatu kenyataan yang sedang dipelajari, melainkan sebagai konstruksi kognitif seseorang terhadap objek, pengalaman, maupun lingkungan. Budiningsih (2005:56) menjelaskan: pengetahuan bukanlah sesuatu yang sudah ada dan tersedia dan sementara orang lain tinggal menerimanya. Galserfeld mengemukakan bahwa ada beberapa kemampuan yang diperlukan dalam proses mengonstruksi pengetahuan, yaitu: (1) kemampuan mengingat dan mengungkapkan kembali pengalaman; (2) kemampuan membandingkan dan mengambil keputusan akan kesamaan dan perbedaan; dan (3) kemampuan untuk lebih menyukai suatu pengalaman yang satu dari pada lainnya (Budiningsih, 2005:57). Piaget mengklasifikasikan tahap perkembangan individu menjadi empat tahapan (Tabel 1).

Tabel 1 Tahap dan Karakteristik Perkembangan Piaget

\begin{tabular}{lcl}
\hline \multicolumn{1}{c}{ Tahap } & $\begin{array}{c}\text { Perkiraan } \\
\text { Usia }\end{array}$ & \multicolumn{1}{c}{ Karakteristik Utama } \\
\hline Sensomotorik & 0-2 tahun & $\begin{array}{l}\text { Intelegensi motorik, dunia di sini dan sekarang, } \\
\text { tidak ada bahasa tidak ada pikiran pada tahap } \\
\text { awal, tidak ada ide tentang realitas objektif }\end{array}$ \\
\hline Pra-operator & 2-7 tahun & $\begin{array}{l}\text { Kemampuan berbahasa lebih meningkat, berpikir } \\
\text { egosentrik, berpikir simbolik, penalaran } \\
\text { didominasi oleh persepsi, pemecahan masalah } \\
\text { lebih intuitif daripada logis }\end{array}$ \\
\hline Operasi Konkret & 7-11 tahun & $\begin{array}{l}\text { Mampu berkonservasi, logika penggolongan dan } \\
\text { relasi, pengertian akan angka, berkembangnya } \\
\text { azas kebalikan dalam berpikir }\end{array}$ \\
\hline Opersi Formal & 12-usia & $\begin{array}{l}\text { Generalisasi pemikiran yang lengkap, berpikir } \\
\text { proporsional, kemampuan memecahkan masalah } \\
\text { abstrak dan hipotesis, berkembangnya idealisme } \\
\text { yang kuat, berpikir kombinasional }\end{array}$ \\
& &
\end{tabular}

Sumber: Syamsul (2010:30) 


\section{Pembelajaran Konstruktivistik dan Miskonsepsi}

Suparno (2005:30) menyatakan secara filosofis terjadinya miskonsepsi pada dapat dijelaskan dengan filsafat konstrukvisme yang menyatakan bahwa pengetahuan itu dibentuk (dikonstruksi) oleh siswa sendiri dalam kontak dengan lingkungan, tantangan, dan bahan yang dipelajari. Oleh karena itu siswa yang mengkonstruksikan pengetahuannya, maka tidak mustahil akan mengalami suatu kesalahan dalam mengkonstruksi. Siswa yang mengonstruksi pengetahuan awalnya sebelum mereka mendapatkan pelajaran formal di sekolah, inilah yang disebut dengan prakonsepsi atau konsep awal siswa. Konsep awal inilah yang sering kali tidak cocok dengan pengetahuan yang diterima oleh para pakar. Hal ini disebabkan siswa tidak berhadapan langsung dengan konsep yang benar. Miskonsepsi yang berasal dari siswa dapat dikelompokkan dalam beberapa hal, yaitu: (1) prakonsepsi atau konsep awal siswa; (2) pemikiran asosiatif; (3) pemikiran humanistik; (4) reasoning yang tidak lengkap atau salah; (5) intuisi yang salah; (6) tahap perkembangan kognitif siswa; (7) kemampuan siswa; dan (8) minat belajar siswa.

Miskonsepsi sebenarnya tidak hanya disebabkan oleh siswa saja, para peneliti miskonsepsi menemukan berbagai hal yang menjadi penyebab miskonsepsi pada siswa. Secara garis besar, penyebab miskonsepsi dapat diringkas dalam lima kelompok, yaitu; siswa, guru, buku teks, konteks, dan metode mengajar. Secara sistematis penyebab miskonsepsi dapat diuraikan dalam bentuk Tabel 2.

Tabel 2 Penyebab Miskonsepsi

\begin{tabular}{ll}
\multicolumn{1}{c}{ Sebab Utama } & \multicolumn{1}{c}{ Sebab Khusus } \\
\hline Siswa & - Prakonsepsi \\
- Pemikiran asosiatif \\
- Pemikiran humanistik \\
- Reasoning yang tidak lengkap/salah \\
- Intuisi yang salah \\
- Tahap pekembangan kognitif siswa \\
- Kemampuan siswa \\
- Minat belajar siswa \\
- Tidak menguasai bahan, tidak kompeten \\
- Bukan lulusan dari bidang ilmunya \\
- Tidak membiarkan siswa mengungkapkan gagasan/ide \\
- Relasi guru-siswa tidak baik \\
- Penjelasan keliru \\
- Salah tulis \\
- Tingkat kesulitan penulisan buku terlalu tinggi bagi \\
- Siswa \\
- Siswa tidak tahu membaca buku teks \\
- Buku fiksi sains kadang-kadang konsepnya \\
- Kenyimpang demi menarik pembaca \\
- Kartun sering memuat miskonsepsi \\
\hline Buku teks
\end{tabular}




\begin{tabular}{ll}
\hline \multicolumn{1}{c}{ Sebab Utama } & \multicolumn{1}{c}{ Sebab Khusus } \\
\hline Konteks & - Pengalaman siswa \\
& - Bahasa sehari-hari berbeda \\
& - Teman diskusi yang salah \\
& - Keyakinan dan agama \\
& - Penjelasan orangtua/orang lain yang keliru \\
& - Konteks hidup siswa (TV, radio, film yang keliru) \\
& - Perasaan senang/tidak senang, bebas/tertekan \\
& - Hanya berisi ceramah dan menulis \\
& - Tidak mengungkap miskonsepsi siswa \\
& - Tidak mengoreksi PR yang salah \\
\hline Cara mengajar &
\end{tabular}

Ada banyak cara untuk mengatasi miskonsepsi dalam mata yang bermanfaat bagi siswa agar miskonsepsi yang dialami siswa dapat minimalkan atau bahkan dihilangkan. Secara garis besar langkah yang digunakan untuk mengatasi miskonsepsi adalah: (1) mencari atau mengungkap miskonsepsi yang dilakukan oleh siswa; (2) mencoba menemukan penyebab miskonsepsi; dan (3) mencari perlakuan yang sesuai untuk mengatasi cara-cara mengatasi miskonsepsi dapat dilihat dari Tabel 3.

\section{Tabel 3 Kiat Mengatasi Miskonsepsi}

\begin{tabular}{|c|c|c|}
\hline Sebab Utama & Sebab Khusus & Kiat Mengatasi \\
\hline Siswa & $\begin{array}{l}\text { - Prakonsepsi } \\
\text { - Pemikiran asosiatif dan } \\
\text { humanistik } \\
\text { - Reasoning yang tidak } \\
\text { lengkap/salah } \\
\text { - Intuisi yang salah } \\
\text { - Tahap pekembangan } \\
\text { kognitif siswa }\end{array}$ & $\begin{array}{l}\text { - Dihadapkan pada kenyataan } \\
\text { - Dihadapakan pada kenyataan } \\
\text { dan peristiwa anomali } \\
\text { - Dilengkapi, dihadapkan pada } \\
\text { kenyataan } \\
\text { - Dihadapkan pada kenyataan, } \\
\text { anomali, rasionalitas } \\
\text { - Diajar sesuai level } \\
\text { perkembangan, mulai dengan } \\
\text { yang konkret ke yang baru } \\
\text { kemudian abstrak } \\
\text { - Dibantu pelan-pelan, proses } \\
\text { - Motivasi variasi pembelaiaran }\end{array}$ \\
\hline Guru/pengajar & $\begin{array}{l}\text { - Tidak menguasai bahan } \\
\text { - Tidak membiarkan siswa } \\
\text { mengungkapkan gagasan/ide } \\
\text { - Relasi guru-siswa tidak baik }\end{array}$ & $\begin{array}{l}\text { - } \text { Belajar lagi } \\
\text { - Memberi waktu siswa untuk } \\
\text { mengungkapkan gagasan } \\
\text { dengan lisan atu tulisan } \\
\text { - Relasi yang enak, akrab, humor }\end{array}$ \\
\hline Buku Teks & $\begin{array}{l}\text { - Penjelasan keliru } \\
\text { - Salah tulis } \\
\text { - Tingkat kesulitan penulisan } \\
\text { buku terlalu tinggi bagi } \\
\text { siswa } \\
\text { - Siswa tidak tahu membaca } \\
\text { buku teks }\end{array}$ & $\begin{array}{l}\text { - Dikoreksi dan dibenarkan } \\
\text { - Dikoreksi secara teliti } \\
\text { - Disesuaikan dengan tingkatan } \\
\text { siswa } \\
\text { - Dilatih oleh guru cara } \\
\text { menggunakan buku teks }\end{array}$ \\
\hline
\end{tabular}




\begin{tabular}{l|ll}
\hline Sebab Utama & \multicolumn{1}{c}{ Sebab Khusus } & \multicolumn{1}{c}{ Kiat Mengatasi } \\
\hline & $\begin{array}{l}\text { Buku fiksi sains kadang- } \\
\text { kadang konsepnya } \\
\text { menyimpang demi menarik } \\
\text { pembaca }\end{array}$ & \\
& $\bullet$ Dibenarkan \\
& Kartun sering memuat \\
& miskonsepsi & • Dikoreksi \\
\hline
\end{tabular}

\section{Penutup}

Mengingat peran guru sebagai pendiagnosis dan fasilitator pembelajaran guna mengatasi kesulitan belajar maka pengembangan Tes Cognitive Diagnostic sudah seharusnya menjadi bagian dari perangkat pembelajaran. Cognitive diagnostic assessment (CDA) atau penilaian diagnosis kognitif untuk pendidikan disusun untuk mengukur struktur pengetahuan secara khusus dan proses kemampuan siswa untuk menyediakan informasi tentang kelemahan dan kekuatan kognitif mereka. Salah satu bentuk kesulitan belajar adalah miskonsepsi.

Ada banyak cara untuk mengatasi miskonsepsi dalam mata pelajaran yang bermanfaat bagi siswa agar miskonsepsi yang dialami siswa dapat minimalkan atau bahkan dihilangkan. Secara garis besar langkah yang digunakan untuk mengatasi miskonsepsi adalah: (1) mencari atau mengungkap miskonsepsi yang dilakukan oleh siswa; (2) mencoba menemukan penyebab miskonsepsi; dan (3) mencari perlakuan yang sesuai untuk mengatasi miskonsepsi. 


\section{DAFTAR RUJUKAN}

Briggs, D. C., dan Alonzo,A.C (2009). The Pstychometric Modeling of Ordered Multiple-Choice Item Responses for Diagnostic Assessment with a Learning Progression. Paper presented at The Learning Progresssion in Science (LeaPS)Conference, June 2009, Iowa City.

Budiningsih, A. 2005. Belajar dan Pembelajaran. Jakarta: Rineka Cipta.

Griel, M. J. 2007. Cognitive Diagnostic Assessment for Education. New York: Cambridge University Press.

Havelock, R. G. 1976. Planning for Innovation Through Dissemination and Utilization of Knowledge. Michigan: Institute for Social Research. The University of Michigan.

Leighton, J. P., dan Gierl, M. J. 2007. Cognitive Diagnostic Assessment: Theory and Applications. Cambridge University Press.

Sukaryono. 2009. Panduan Guru Bimbingan \& Konseling untuk SD, SLTP, dan SLTA. Malang: Universitas Negeri Malang.

Suparmo, P. 2005. Miskonsepsi dan Perubahan Konsep dalam Pendidikan Fisika. Jakarta: Grasindo.

Thalib, S. B. 2010. Psikologi Pendidikan Berbasis Analisis Empirirs Aplikatif. Jakarta: Kencana Prenada Media Group.

Trianto. 2007. Model-Model Pembelajaran Inovatif Berorientasi Konstruktivistik. Jakarta: Prestasi Pustaka. 